\title{
Changes in stimulus salience as a result of stimulus preexposure: Evidence from aversive and appetitive testing procedures
}

\author{
C. A. J. BLAIR and GEOFFREY HALL \\ University of York, York, England
}

\begin{abstract}
In two experiments, rats received preexposure to three compound flavor stimuli, $\mathrm{AX}, \mathrm{BX}$, and $\mathrm{CX}$, where $\mathrm{X}$ represents a saline solution. AX and BX were presented in alternation; $\mathrm{CX}$, on a separateblock of trials. The value of $\mathrm{X}$ was then modified, being devalued by aversive conditioning in Experiment 1, and rendered valuable by the induction of a state of salt need in Experiment 2 . When given a choice between BX and CX, the rats consumed more of BX than of CX in Experiment 1, and more of CX than of BX in Experiment 2, suggesting that B and $C$ differed in their ability to modulate the response governed by the $\mathrm{X}$ element. It was suggested that blocked preexposure to $\mathrm{CX}$ reduces the salience of the $\mathrm{C}$ stimulus but that the salience of $\mathrm{B}$ is maintained by preexposure in which BX is alternated with $\mathrm{AX}$. The implications of this result for the phenomenon of perceptual learning are discussed.
\end{abstract}

Our standard theories of classical conditioning (see, e.g., Wagner, 1981) assume the existence of a representational node for each of the events that can be shown to be effective as a conditioned or unconditioned stimulus (CS or US). Learning is held to occur when two nodes are activated concurrently and to consist of changes in the strength of associative links between them. Since the degree of change will depend on the extent to which each of the nodes is activated, it is important to be able to specify the relationship between the external stimulus and the level of activity that its presentation induces in its node. The usual assumption has been that the level of activity in a node will be determined directly by the intensity (or salience) of the stimulus that is applied. But Hall (2003) has challenged this assumption, arguing, on the basis of evidence from experiments on perceptual learning, that the ability of a given stimulus to activate its node can change with experience-that mere exposure to a stimulus can engage a learning process that produces a change in the effective salience of the stimulus. Hall suggests that repeated exposure to a stimulus will normally result in a loss of salience but that exposure to intermixed (alternating) presentations of two similar stimuli will maintain, or even enhance, the effective salience of their distinctive features. The experiments to be described in this article were designed to explore the latter suggestion, and, in particular, to assess whether the evidence that has been interpreted as indicating changes in

This work was supported by a studentship from the Biotechnology and Biological Science Research Council to Chris Blair. We thank C. Bonardi, E. Mondragón, and M. Symonds for helpful discussion. Correspondence concerning this article should be addressed to either C. A. J. Blair or G. Hall, who are both at the Department of Psychology, University of York, York YO10 5DD, England (e-mail: GH1 @ york.ac.uk). salience can be explained in terms of known associative principles.

The experimental evidence on which Hall's (2003) account is based comes, in part, from a recent series of studies reported by Blair and Hall (2003) examining generalization in flavor aversion learning after preexposure to the stimuli. Our basic procedure made use of three flavors, $\mathrm{A}, \mathrm{B}$, and $\mathrm{C}$, that were rendered similar by the addition of an explicit element (X) common to each. (Here A represents a lemon solution; $\mathrm{B}$ and $\mathrm{C}$ represent sucrose and saline solutions, counterbalanced; and $\mathrm{X}$, a solution of quinine.) One of these compounds (AX) was trained as a $\mathrm{CS}$ in the flavor-aversion paradigm; the aim of the experiment was to see how different schedules of preexposure to the stimuli would influence generalization from AX to the test compounds BX and CX. In the preexposure phase, there were four presentations of each of the three stimuli. Presentations of CX occurred in one block of trials; presentations of $\mathrm{AX}$ and $\mathrm{BX}$, however, were intermixed, occurring on alternate trials. It was found (Blair \& Hall, 2003, Experiment 1) that the aversion established to AX generalized less readily to BX than to CX. In explaining these results, we argued that the aversion displayed on the test trials in this procedure would be largely determined by the ability of the conditioned element, $\mathrm{X}$, to evoke its conditioned response (CR) and that the differential responding shown to BX and CX indicated that the $\mathrm{B}$ and $\mathrm{C}$ differed in their ability to interfere with the expression of this CR. We suggested that the effective salience of $\mathrm{B}$ and $\mathrm{C}$ had been modified during the preexposure phase- that the salience of $\mathrm{C}$ had declined during the block of exposure trials with $\mathrm{CX}$ but that alternating trials with $\mathrm{AX}$ and $\mathrm{BX}$ had maintained or enhanced the salience of their unique features (and in particular of B). The less salient $C$ stimulus would be less 
likely to interfere with the ability of the conditioned element $\mathrm{X}$ to evoke its $\mathrm{CR}$ than would the more salient $\mathrm{B}$ stimulus, producing the result obtained.

The interpretation offered by Hall (2003) implies the existence of a novel (or, at least, nonassociative) learning process that modulates the perceptual effectiveness of stimuli. But before we commit ourselves to this conclusion, it is important to be sure that the effects on which it is based cannot be explained in terms of standard associative mechanisms. And, as Hall (2003) has acknowledged, the associative account of perceptual learning proposed by McLaren and Mackintosh (2000; see also McLaren, Kaye, \& Mackintosh, 1989) can supply an explanation for the results reported by Blair and Hall (2003, Experiment 1).

McLaren and Mackintosh (2000) point out that exposure to a compound stimulus will result in the formation of excitatory associations among the elements of the compound (Rescorla \& Cunningham, 1978). The preexposure procedure used by Blair and Hall (2003) can thus be expected to establish associations between $\mathrm{A}$ and $X, B$ and $X$, and $C$ and $X$. That between $A$ and $X$ could contribute to the magnitude of the CR observed on the test trial with $\mathrm{CX}$. Conditioning with $\mathrm{AX}$ as the $\mathrm{CS}$ will endow both $\mathrm{A}$ and $\mathrm{X}$ with associative strength, and the aversion shown to CX on the test will no doubt be determined largely by the strength of the conditioned $\mathrm{X}$ element. But although A is not presented on the test, its strength could still play a role, because the existence of the A-X association would allow the $\mathrm{X}$ element of the test stimulus to contact the US representation by way of the chain X-A-US. Such a process can be expected to operate when CX is the test stimulus, but when BX is the test stimulus another factor must be taken into account. According to standard associative theory, preexposure consisting of alternating trials with $\mathrm{AX}$ and $\mathrm{BX}$ will not only establish excitatory associations between the elements of each compound, but also result in the formation of inhibitory associations between their unique features. In particular, once the excitatory, within-compound, A-X association has been established, presentation of $\mathrm{BX}$ will activate the representation of the absent A element (by way of the $\mathrm{X}-\mathrm{A}$ association), a circumstance that, according to Wagner (1981), will result in the formation of inhibitory links between $\mathrm{B}$ and $\mathrm{A}$ and between $\mathrm{X}$ and $\mathrm{A}$. The excitatory link between $\mathrm{X}$ and $\mathrm{A}$ will be reestablished on the next $\mathrm{AX}$ trial, but $\mathrm{B}$, being a unique predictor of the absence of A, will acquire net inhibitory strength. As a consequence, on test trials with $\mathrm{BX}$, activation of $A$ by way of the $\mathrm{X}-\mathrm{A}$ link will be inhibited by the presence of $\mathrm{B}$, and the associative strength acquired by A will not be able to contribute to the CR.

In an attempt to test the validity of this account, we conducted a further study (Blair \& Hall, 2003, Experiment 5) in which, as before, rats received exposure consisting of alternating presentations of $\mathrm{AX}$ and $\mathrm{BX}$ and a separate block of CX trials. They then received aversion conditioning in which the $\mathrm{X}$ element (rather than the AX compound as in the previous experiment) was used as the CS. When tested with BX and CX, the animals again consumed less of CX than of BX. This is the result to be expected if the test performance depends on a difference between $B$ and $C$ in their ability to interfere with the expression of the CR governed by X; the more salient $\mathrm{B}$ will be more effective in this regard than the less salient $\mathrm{C}$, both when $\mathrm{X}$ has been conditioned in compound with $\mathrm{A}$, as in the previous experiment, and when $\mathrm{X}$ has been conditioned alone. McLaren and Mackintosh (2000), however, predict that there should be no difference on test when $\mathrm{X}$ has been conditioned alone. According to their account, BX differs from CX in that B is able to inhibit the A representation whereas $\mathrm{C}$ is not; but this difference will be relevant only when the conditioning procedure is one that has endowed A with some associative strength (as when conditioning is given with AX); it should not affect performance when conditioning has been given with $\mathrm{X}$ alone.

Given that the results of Blair and Hall's (2003) Experiment 5 appear to have theoretically important implications, we attempted, in the experiments to be reported here, to confirm and extend them. In the present Experiment 1 , we adopted essentially the same design and procedure, but we changed the nature of the flavors used; in particular, we used saline rather than quinine as the $\mathrm{X}$ element. To anticipate, we succeeded in replicating the result obtained by Blair and Hall in their Experiment 5, thus extending the generality of the effect. More important, the outcome of Experiment 1 formed the basis for a further investigation of the phenomenon. According to the interpretation offered by Hall (2003), the difference between $\mathrm{BX}$ and $\mathrm{CX}$ on test derives from a difference in the ability of $\mathrm{B}$ and $\mathrm{C}$ to interfere with the responding governed by the conditioned $\mathrm{X}$ element. In the experiments described so far, $\mathrm{X}$ has been subjected to aversive conditioning so that the effect of presenting the salient B element along with $X$ has been to attenuate the suppression of consumption generated by X. But if Hall's (2003) interpretation is correct, B should be more effective than C in attenuating any response controlled by the $\mathrm{X}$ element-if, for instance, $\mathrm{X}$ is particularly valued by the rat, then the presence of B in the BX compound can be expected to lead to a reduction in the amount consumed (compared with the amount of CX consumed).

Using saline as the $\mathrm{X}$ element allows a test of this prediction. Injecting rats with a mixture of furosemide and deoxycorticosterone acetate (Furo-Doca) induces a state of salt need and renders them eager to consume a saline solution (Cruz, Perelle, \& Wolf, 1977). Animals in this state should readily consume compounds such as BX and $\mathrm{CX}$, which contain saline. But if alternating preexposure renders B relatively salient (with respect to the $\mathrm{C}$ element preexposed in a block of CX trials), then they will be less ready to consume the BX compound (in which the presence of $B$ will interfere with the perception of $\mathrm{X}$ ) than the $\mathrm{CX}$ compound. This prediction was tested in Experiment 2. 


\section{EXPERIMENT 1}

In this experiment, all subjects (rats) received an initial preexposure phase consisting of trials with three compound flavor stimuli, AX, BX, and CX. A, B, and C were commercially produced food flavorings; $\mathrm{X}$ was a saline solution. This was followed by aversion conditioning with $\mathrm{X}$ as the CS. All then received a two-bottle test in which the compound $\mathrm{BX}$ and $\mathrm{CX}$ were presented. (In the experiment by Blair \& Hall, 2003, on which this study was based, the test procedure consisted of a series of single-bottle tests. The use of a two-bottle test in the present experiment was dictated by the desire to match the procedure with that to be used in Experiment 2, in which the use of a two-bottle test was dictated by the particular procedures employed.) If this procedure should generate an effect equivalent to that demonstrated by Blair and Hall (2003, Experiment 5), one would expect to find that the subjects would consume more of BX than of CX.

\section{Method}

Subjects and Apparatus. The subjects were 8 experimentally naive male hooded Lister rats with a mean ad-lib weight of $367 \mathrm{~g}$ at the start of the experiment. The rats were housed singly, with continuous access to food, in a colony room that was artificially lit from 8:00 a.m. to 8:00 p.m. each day. Access to water was restricted as detailed below. Presentations of the various solutions used as the stimuli in these experiments were given in the home cages.

The solutions used as experimental stimuli were administered at room temperature in 50-ml plastic centrifuge tubes equipped with a rubber stopper to which was fitted a stainless steel, ball-bearingtipped spout. The following solutions were used: A compound consisting of $0.08 \mathrm{M}$ saline $(\mathrm{NaCl})$ and almond $(2 \% \mathrm{v} / \mathrm{v}$ almond flavoring supplied by Supercook, Leeds, U.K.); a compound of $0.08 \mathrm{M}$ saline and vanilla ( $1 \% \mathrm{v} / \mathrm{v}$ Supercook vanilla flavoring) sulfate; and a compound of $0.08 \mathrm{M}$ saline and peppermint $(0.5 \% \mathrm{v} / \mathrm{v}$ Supercook peppermint flavoring). Consumption was measured by weighing the tubes before and after trials, to the nearest $0.1 \mathrm{~g}$. The US for the conditioning trials was an intraperitoneal injection of $0.3 \mathrm{M}$ lithium chloride $(\mathrm{LiCl})$ at $10 \mathrm{ml} / \mathrm{kg}$ of body weight.

Procedure. A schedule of water deprivation was initiated by removing the standard water bottles overnight. On each of the following 3 days, access to water was restricted to two daily sessions of $30 \mathrm{~min}$, at 11:00 a.m. and 5:00 p.m. Presentation of fluids continued to be given at these times throughout the experiment.

Over the next 6 days (the preexposure phase), all subjects received four presentations of each of the three compound flavors AX, BX, and CX. Half the animals were first given 4 days of intermixed access to flavors $\mathrm{AX}$ and $\mathrm{BX}$, with $10 \mathrm{ml}$ of $\mathrm{AX}$ being presented during the first daily drinking session and $10 \mathrm{ml}$ of $\mathrm{BX}$ during the second. This was followed by 2 days of blocked presentations of CX, in which $10 \mathrm{ml}$ of this flavor was made available in both morning and afternoon drinking sessions. The remainder of the subjects received the blocked presentations of $\mathrm{CX}$ on the first 2 days of the phase followed by 4 days of AX and BX. For all animals, flavor A was peppermint and flavor $\mathrm{X}$ was saline. The critical test flavors, $\mathrm{B}$ and $C$, were counterbalanced with half the animals receiving vanilla as $\mathrm{B}$ and almond as $\mathrm{C}$, and half receiving the reverse arrangement.

Three conditioning trials followed. The first was given in the morning session the day after preexposure ended. It consisted of a 30-min presentation of $9 \mathrm{ml}$ of $\mathrm{X}$, followed immediately by an injection of $\mathrm{LiCl}$. The rats were given free access to water in the afternoon session. The next day was a recovery day on which animals were given unrestricted access to water on both drinking sessions. The second conditioning trial, given in the morning session of the next day, was identical to the first and was followed by a further recovery day. The third conditioning trial was identical to the second. Water was again available in the afternoon session following this conditioning trial, and 1 further recovery day preceded the test phase of the experiment.

On the following morning session, subjects were given a 30-min choice test, receiving access to $30 \mathrm{ml}$ of $\mathrm{BX}$ and to $30 \mathrm{ml}$ of CX in two separate drinking tubes presented simultaneously. The two tubes were inserted into the cage on either side of the aperture used for presentations of the single tube given during earlier stages of training. The two spouts were separated by a distance of $5 \mathrm{~cm}$. The position of the tubes was counterbalanced in such a way that half the rats were presented with $\mathrm{BX}$ on the right, and half with $\mathrm{CX}$ on the right. Water was made available for $30 \mathrm{~min}$ in the afternoon session. Over the next 4 days, four further test sessions were given, the procedure being identical to that just described.

\section{Results and Discussion}

The rats consumed all of the fluid that was made available on the preexposure sessions. The conditioning procedure successfully established an aversion to X. Group mean consumption was $9.31 \mathrm{ml}$ on Trial $1,9.32 \mathrm{ml}$ on Trial 2, and $4.08 \mathrm{ml}$ on Trial 3. All subjects showed a reduction in consumption from Trial 1 to Trial 3.

Group mean consumption scores for the test sessions are presented in Figure 1. The rats consumed rather little of either solution on the first test session, but consumption increased over sessions, presumably as a result of extinction of the aversion conditioned to X. The subjects consumed more of BX than of CX on each of the five tests, with the difference between the means for con-

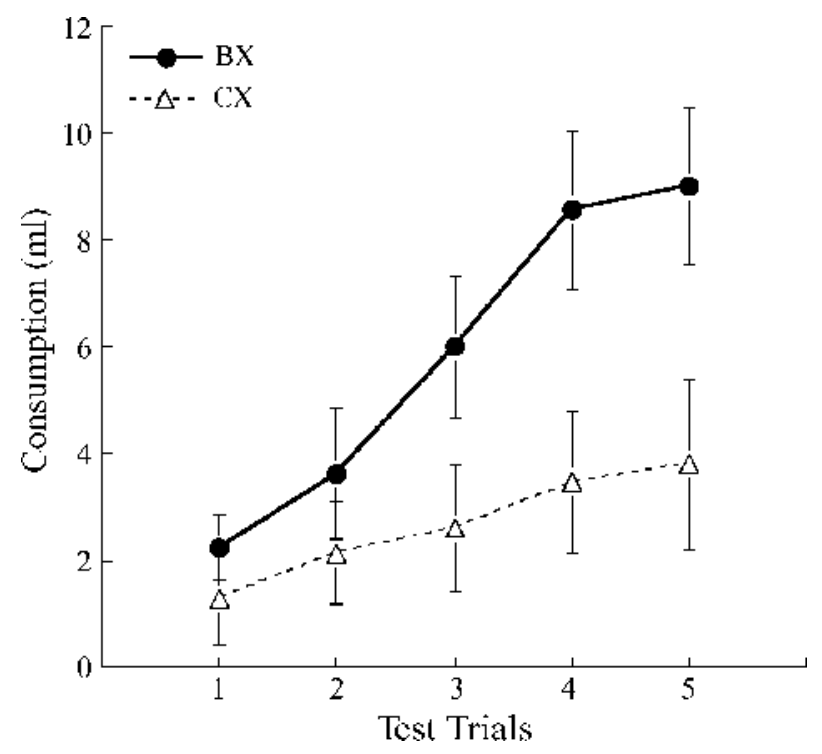

Figure 1. Experiment 1: Mean consumption of flavor compounds $B X$ and $C X$ over five two-bottle test trials. The rats had all received preexposure consisting of a block of trials with $\mathrm{CX}$ and alternating trials with $\mathrm{AX}$ and $\mathrm{BX}$, prior to aversion conditioning with $X$. Error bars represent within-subjects standard error, computed on scores adjusted for variation between subjects (Bakeman \& McArthur, 1996). 
sumption of the two flavors increasing throughout. This description of the results was confirmed by an analysis of variance (ANOVA) conducted on the data summarized in the figure, with test stimulus (BX or $\mathrm{CX}$ ) and trial as the factors. There was no significant main effect of test stimulus $[F(1,7)=2.18$; here and elsewhere a significance level of $p<.05$ was adopted], but there was a significant effect of trial $[F(4,28)=16.32]$, and, critically, a significant interaction between trial and stimulus $[F(4,28)=4.54]$. Pairwise comparisons using Tukey's test revealed that the scores for the two flavors differed significantly on Trials 4 and 5 .

The data presented in the figure pool the results for two subgroups, one presented with CX on the first block of preexposure trials, the other presented with $\mathrm{CX}$ on the second block of preexposure trials. With only 4 animals in each of these subgroups, our ability to detect any difference between them will be limited. There was some indication, however, that the effect of interest (the low level of consumption of CX on test) was more substantial in the subgroup given CX in the second block. Pooling over all test trials showed that this group drank a mean of $5.7 \mathrm{ml}$ of $\mathrm{BX}$ and $1.6 \mathrm{ml}$ of $\mathrm{CX}$; the equivalent scores for the group given CX first were $6.0 \mathrm{ml}$ and $3.8 \mathrm{ml}$. This difference between the subgroups was not, however, statistically reliable. An ANOVA paralleling that just described, but including subgroup as a variable, yielded neither a significant main effect of this variable $[F(1,6)=1.49]$ nor any significant interaction-for the subgroup $\times$ stimulus interaction, $F<1$; for the triple interaction, $F(4,24)=1.60$.

Although this experiment made use of different flavors as the stimuli and a different test procedure, its results were entirely consistent with those reported by Blair and Hall (2003, Experiment 5). Rats that had received aversion conditioning with flavor $\mathrm{X}$ drank more of it on test when it was presented in compound with B than when it was presented in compound with C. This outcome is thus in accord with the suggestion that the schedule of preexposure used in the first phase of the experiment rendered stimulus B effectively more salient than stimulus $\mathrm{C}$ and thus better able to disrupt the expression of the aversion governed by $\mathrm{X}$.

\section{EXPERIMENT 2}

Our proposal that the results of Experiment 1 reflect differences in salience between $B$ and $C$ depends on the (surely plausible) assumption that a more salient stimulus will be more effective than a less salient stimulus in interfering with the response elicited by some other stimulus with which it is compounded. In Experiment 1, this response was the aversion to $\mathrm{X}$ established by an aversive conditioning procedure in which $\mathrm{X}$ served as the CS. But if our interpretation is correct, B and C should differ in their ability to modulate any response controlled by X. In the present experiment, we made use of the fact that $X$ was a solution of saline and that an injection of FuroDoca would increase the readiness of rats to consume saline. We gave rats preexposure consisting of alternating trials with $\mathrm{AX}$ and $\mathrm{BX}$ and a separate block of CX trials. We then gave them an injection of Furo-Doca followed by a test session in which BX and CX were presented. We expected that the rats in a state of salt need would tend to consume both of these compounds readily, to the extent that they were able to perceive the saline component. The question of interest was whether the supposedly more salient $\mathrm{B}$ element would interfere with this tendency more than the less salient $\mathrm{C}$ element would, resulting in a greater consumption of CX than of BX.

It will be noted that, in this experiment, the looked-for pattern on the test session (more consumption of CX than of BX) was the opposite of that predicted (and found) in Experiment 1. To find this pattern would allow us to rule out some possible, but theoretically uninteresting, explanations for the result of that experiment. One of these was the possibility that the preexposure schedules used in these experiments were differentially effective in their ability to produce habituation. If habituation occurs more readily with the alternating schedule than with the blocked arrangement, then the BX compound would be less likely to evoke neophobia than would the CX compound, resulting in greater consumption of BX than CX-the result obtained in Experiment 1. But this account cannot predict greater consumption of CX than of BX, the result anticipated in this experiment.

An alternative interpretation of the results of Experiment 1 can be derived from the fact that in that experiment, presentations of $\mathrm{BX}$ were always given during afternoon sessions in preexposure, whereas CX also occurred during morning sessions (but see Blair \& Hall, 2003, Experiment $1 \mathrm{~B}$ ). Aversion conditioning to $X$ occurred during a morning session. Accordingly, if time of day can serve as a cue that mediates generalization, it might be argued that generalization would be greater to CX than to $\mathrm{BX}$, producing the effect seen in Experiment 1. But this argument does not apply to the present experimentgiven that the procedure does not involve a conditioning phase, there is no basis on which the time-of-day factor can play a role and therefore no reason to predict any difference in consumption between CX and BX on the test.

Finally, it could be argued that the results of Experiment 1 , in which the difference between BX and CX developed only over the course of several nonreinforced test sessions, might be a consequence of a difference between the two test stimuli in the rate at which extinction occurs. Given that the aversion shown on test will be largely a consequence of the associative strength governed by a stimulus element, $\mathrm{X}$, that is common to both test compounds, it is not clear how such a difference might arise. Nonetheless, it is worth noting that differential extinction could not easily explain the anticipated results of the present experiment, in which the test consisted of a single presentation of $\mathrm{BX}$ and $\mathrm{CX}$.

\section{Method}

The subjects were 16 experimentally naive male hooded Lister rats with a mean ad-lib weight of $352 \mathrm{~g}$ at the start of the experi- 
ment. The experiment was run in two replications, each using 8 animals. In the first replication, 1 animal became ill prior to the test phase so that data were available for 15 subjects. The flavors used as stimuli were those described for Experiment 1. The treatment used to induce a sodium appetite was a subcutaneous injection of $0.5 \mathrm{ml}$ of a mixture of $10 \mathrm{mg}$ furosemide (Furo) and $5 \mathrm{mg}$ of deoxycorticosterone acetate (Doca) dispersed in $20 \mathrm{ml}$ of distilled water with one drop of Tween 80 .

The subjects initially received exposure to $\mathrm{AX}, \mathrm{BX}$, and $\mathrm{CX}$, the procedure being identical to that described for the preexposure phase of Experiment 1. One hour after the end of the final preexposure session (the afternoon session on Day 6 of preexposure), all animals received an injection of Furo-Doca. The food was then removed from the home cages in the colony room, and the subjects were given free access to distilled water overnight. On the following day, the distilled water was removed from the cages $3 \mathrm{~h}$ prior to the test session (the morning drinking session). On test, the subjects were given a free-access choice test, receiving $30 \mathrm{ml}$ of flavor BX and an identical volume of flavor CX, in the same manner as in Experiment 1 . Only one such test was given (the effects of the FuroDoca injection being short-lived).

\section{Results and Discussion}

The rats consumed all of the fluid made available on each of preexposure sessions, with no evidence of neophobia.

The results of the test session, group means for consumption of BX and CX, are presented in Figure 2. It shows that subjects consumed more of $\mathrm{CX}$ than of $\mathrm{BX}$. A within-subjects, one-way ANOVA confirmed that the difference between the two test stimuli was statistically reliable $[F(1,14)=5.42]$.

As in the previous experiment, we looked separately at the performance of the two counterbalanced subgroups, which were given $\mathrm{CX}$ presentations as the first or as the second block of preexposure trials. In this case, the dif-

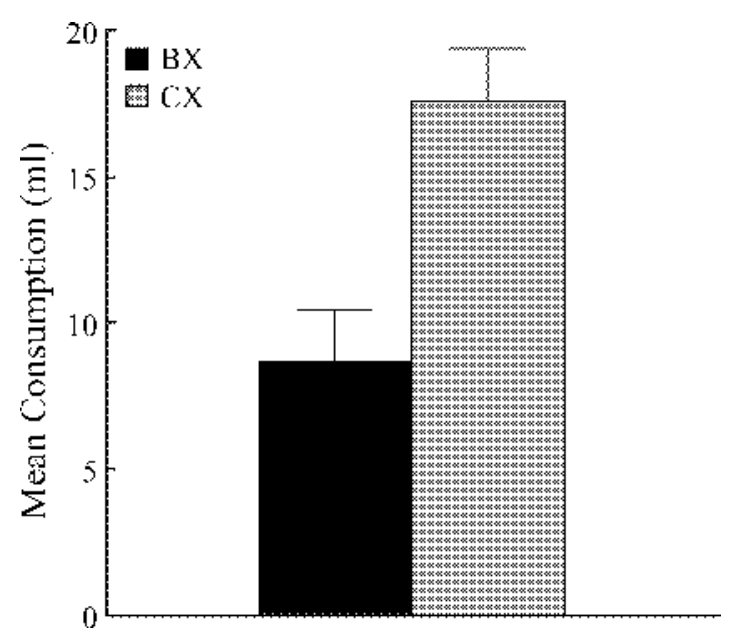

Figure 2. Experiment 2: Mean consumption of flavor compounds $B X$ and $C X$ on the choice test. The rats had all received preexposure consisting of a block of trials with $\mathrm{CX}$ and alternating trials with $\mathrm{AX}$ and $\mathrm{BX}$, followed by the ind uction of a salt need immediately prior to the test. Error bars represent within-subjects standard error, computed on scores adjusted for variation between subjects (Bakeman \& McArthur, 1996). ference between the groups was quite marked. The effect shown in the figure was almost entirely a consequence of the behavior of the subgroup $(n=8)$ given $\mathrm{CX}$ first. This group consumed $22.6 \mathrm{ml}$ of $\mathrm{CX}$ and $7.1 \mathrm{ml}$ of BX. The subgroup given CX second $(n=7)$ consumed rather less overall, and the difference between the scores for BX (11.2 ml) and CX (11.9 ml) was negligible. An ANOVA conducted on these data revealed a significant main effect of test stimulus [BX or CX; $F(1,13)=6.25]$ and no significant main effect of subgroup $[F(1,13)=$ 3.76], but there was a significant interaction between these variables $[F(1,13)=5.24]$. Analysis of simple effects showed that the scores for BX and CX differed significantly in the subgroup given CX first $[F(1,13)=$ 12.29], but not in the subgroup given $C X$ second $(F<1)$.

The theoretical implications of this difference between the subgroups will be taken up in the General Discussion. For the time being, we will simply note that the overall pattern of the results (as shown in Figure 2) accords with the interpretation that we offered for the results of Experiment 1. In that experiment, the stimulus element $\mathrm{X}$ was made aversive and the animals consumed less of $\mathrm{CX}$ than of $\mathrm{BX}$ on test, a result we interpreted as showing that $\mathrm{B}$ was more effective than $\mathrm{C}$ in modulating the response controlled by $\mathrm{X}$. In this experiment, stimulus element $\mathrm{X}$ was made desirable by the administration of Furo-Doca just after preexposure. The resulting salt need meant that when given a choice, subjects were motivated to consume the flavor compound that they perceived as being richer in salt. Our prediction, therefore, was that the perceptually salient B element would be more likely to interfere with perception of the desirable salt than would the less salient $\mathrm{C}$ element, leading to greater consumption of $\mathrm{CX}$ than of $\mathrm{BX}$ - the result that was obtained.

As we pointed out in the introduction to this experiment, the finding of greater consumption of CX than of $\mathrm{BX}$ in the present experiment rules out some, relatively trivial, explanations that might be offered for the results of Experiment 1. It also allows us to address a possible explanation that can be derived from an elaboration of the theory proposed by McLaren et al. (1989). According to that theory, it will be recalled, the preexposure schedule employed in these experiments will result in the formation of excitatory links between $\mathrm{X}$ and each of $\mathrm{A}$, $\mathrm{B}$, and $\mathrm{C}$; it will also allow the formation of inhibitory links between $\mathrm{A}$ and $\mathrm{B}$. When animals are conditioned with $\mathrm{X}$ (as in Experiment 1), the excitatory $\mathrm{X}-\mathrm{C}$ link should generate activity in the representation of stimulus $\mathrm{C}$; but the existence of inhibitory A-B links might limit the extent to which the representations of these stimuli can be activated. Finally, if it is accepted that the associatively activated representation of a stimulus can undergo conditioning (see Hall, 1996), it follows that C will be more likely than A or B to acquire associative strength during reinforced $X$ trials. Differences in the acquisition of strength by $\mathrm{C}$ could then explain why the animals showed a greater aversion to $\mathrm{CX}$ than to BX in Ex- 
periment 1 . Resting, as it does, on a number of debatable assumptions, this explanation may seem implausible, but there is nothing in the results of Experiment 1 to rule it out entirely. It cannot apply to the results of the present experiment, however, since the mechanism proposed depends critically on events occurring during the conditioning trials with $\mathrm{X}$. The central feature of this experiment was that the value of $X$ was modified by means of a procedure that did not involve presentations of $\mathrm{X}$.

\section{GENERAL DISCUSSION}

Taken together with the results reported by Blair and Hall (2003), the experiments described here allow the following conclusions. Preexposure to the compound stimuli AX, BX, and CX will, among other things, modify the properties of their unique features, $\mathrm{A}, \mathrm{B}$, and C. When the preexposure consists of alternating trials with $\mathrm{AX}$ and $\mathrm{BX}$, and a separate block of CX trials, the consequence appears to be that the effective salience of the B element (and presumably also of the A element, although this was not tested directly) is greater than that of the $\mathrm{C}$ element. This difference is evidenced by the effects of compounding $B$ and $C$ with another element $(X)$. When $\mathrm{X}$ is aversive, compounding it with $\mathrm{B}$ results in less of an aversion than does compounding it with $\mathrm{C}$. When $\mathrm{X}$ has a positive value, compounding it with $\mathrm{B}$ results in less being consumed than when it is compounded with $\mathrm{C}$. This pattern of results is parsimoniously explained in terms of the proposal that the more salient $\mathrm{B}$ is more likely to interfere with the ability of $\mathrm{X}$ to evoke its response than is the less salient $C$.

The proposal that alternating exposure to two similar stimuli will enhance the salience of their unique elements (or at least results in a lesser loss than is produced by repeated presentation of just one stimulus) has the capability to explain a wide range of perceptual learning effects. The central feature of these effects (for a recent review, see Hall, 2001) is that appropriately scheduled exposure to similar stimuli can increase the ease with which they can subsequently be discriminated. The essence of discrimination learning is that behavior must come to be controlled by the unique, distinguishing features of the stimuli rather than by features they hold in common. A learning process that enhances the (relative) salience of the unique features of similar stimuli would thus be capable of generating the observed effects.

It remains to explain the nature of the learning process responsible for changes in stimulus salience, and here we have little more than speculation to offer. That repeated exposure to a given stimulus (such as CX in the present experiments) might cause a loss of salience (in both $\mathrm{C}$ and $\mathrm{X}$ ) is not problematic. The phenomenon of habituation demonstrates that repeated presentation of a stimulus that initially evokes an overt response will reduce the effectiveness of the stimulus in this respect. Although they do not evoke any obvious overt response, it is reasonable to assume that the stimuli presented in the pre- exposure phase of these experiments will also undergo habituation and thus become less effective at eliciting whatever unobserved covert response they would normally evoke in the animal; it is this loss of effectiveness that we have equated with a change in stimulus salience. The real problem is to explain why this loss of effectiveness should be attenuated or reversed for A and B when preexposure consists of alternating trials with $\mathrm{AX}$ and BX.

According to Gibson's (1969) account of perceptual learning, exposure to similar stimuli will engage a differentiation process that will enhance the perceptual effectiveness of unique stimulus features. Differentiation is held to occur more readily when the subject has a chance to compare the relevant stimuli. It might be suggested, then, that alternating preexposure is particularly effective in maintaining or strengthening the effectiveness of A and B because these stimuli are presented according to a schedule that promotes stimulus comparison. The obvious problem with this suggestion is that although AX and BX were indeed presented in alternation in these experiments, the interval between successive trials was at least $5 \mathrm{~h}$, making it unlikely that any activation produced by presentation of the first stimulus would still be ongoing when the second stimulus occurred. What does seem possible, however, is that the central representation of each of the critical stimulus features will be activated associatively on each trial (after the first) in the alternating schedule. Alternating trials with $\mathrm{AX}$ and $\mathrm{BX}$ can be expected to establish and maintain excitatory connections between $\mathrm{X}$ and $\mathrm{A}$ and between $\mathrm{X}$ and $\mathrm{B}$, allowing $\mathrm{A}$ to be activated associatively on BX trials and $\mathrm{B}$ to be activated associatively on AX trials. Hall (2003) has advanced the hypothesis that the associative activation of a stimulus representation in the absence of direct presentation of the stimulus itself will act to reverse the loss of salience that occurs when the stimulus itself is presented.

Comparison of the counterbalanced subgroups of the present experiments (those given CX preexposure in the first block vs. those given CX preexposure in the second block) allows a test of this hypothesis. For both subgroups, the alternating schedule used for presentations of $\mathrm{AX}$ and $\mathrm{BX}$ ensures that associative activation of the representation of B will occur regularly on AX trials. According to the hypothesis, the salience of B should therefore be maintained or enhanced in both. The fate of the $\mathrm{C}$ element will, however, differ in the two subgroups. When CX is presented second during preexposure, there will be no opportunity for the associative activation of $\mathrm{C}$ in the absence of the stimulus, and its decline in salience should proceed unhindered. But when CX is presented first, the formation of the within-compound $\mathrm{C}-\mathrm{X}$ association during the first block of trials will mean that $\mathrm{C}$ can be activated associatively on the subsequent $\mathrm{AX}$ and BX trials (at least until the point at which these trials result in extinction of the $\mathrm{X}-\mathrm{C}$ association). $\mathrm{C}$ should therefore lose salience less readily in the latter condition. 
It follows that the difference in effectiveness between $\mathrm{B}$ and $\mathrm{C}$ on the test should be greater in the subgroup that received CX during the second block of preexposure trials than in the subgroup that received $\mathrm{CX}$ in the first block.

Unfortunately, the results of the present experiments are equivocal on this issue. In Experiment 1, the means for the two subgroups were entirely in accord with our prediction; the subgroup given $\mathrm{CX}$ first in preexposure drank more of CX on the test than did the subgroup given $\mathrm{CX}$ second, implying that the salience of $\mathrm{C}$ was greater in the former group than in the latter. That the difference between the subgroups was small (and not statistically reliable) would also be expected, given that the CX-first arrangement supplies conditions that are less than optimal for the associative activation of $\mathrm{C}$ (and thus for producing the increase in effective salience envisaged by our interpretation). In this subgroup, $\mathrm{C}$ may be activated associatively during the initial presentations of $\mathrm{AX}$ and $\mathrm{BX}$ that follow exposure to CX, but, in the absence of further CX trials, it is to be expected that extinction of the within-compound association between $\mathrm{X}$ and $\mathrm{C}$ will limit this effect just to these initial trials. This would explain why consumption of CX was only slightly higher in the subgroup for which CX was presented first, and why, overall, the means indicate a clear perceptual learning effect (significantly higher consumption of BX than CX) in both subgroups.

The results for the equivalent analysis of Experiment 2 are more problematic. Here the subgroup given $\mathrm{CX}$ first (but not that given CX second) showed a profound difference in consumption of the two test solutions-the reverse of the effect predicted (and obtained in Experiment 1). We can see no obvious explanation for this outcome, and we will need to carry out further work to confirm its reliability. However this may turn out, it is encouraging that the overall findings of Experiment 2 are largely in accord with conclusions drawn from a body of work that has, until now, relied on the conditioned flavor aversion procedure. Some aspects of the re- sults are challenging for the hypothesis offered by Hall (2003), but, importantly for our present concern, the basic pattern obtained is not to be easily explained by established associative theories of perceptual learning as they are currently formulated.

\section{REFERENCES}

BAKeman, R., \& McArthur, D. (1996). Picturing repeated measures: Comments on Loftus, Morrison, and others. Behavior Research Methods, Instruments, \& Computers, 28, 584-589.

Blair, C. A. J., \& Hall, G. (2003). Perceptual learning in flavor aversion: Evidence for learned changes in stimulus effectiveness. Journal of Experimental Psychology: Animal Behavior Processes, 29, 39-48.

Cruz, C. E., Perelle, I. B., \& Wolf, G. (1977). Methodological aspects of sodium appetite: An addendum. Behavioural Biology, 20, 96-103.

Gibson, E. J. (1969). Principles of perceptual learning and development. New York: Appleton-Century-Crofts.

HALL, G. (1996). Learning about associatively activated stimulus representations: Implications for acquired equivalence and perceptual learning. Animal Learning \& Behavior, 24, 233-255.

HALL, G. (2001). Perceptual learning: Association and differentiation. In R. R. Mowrer \& S. B. Klein (Eds.), Handbook of contemporary learning theories (pp. 367-407). Mahwah, NJ: Erlbaum.

HALL, G. (2003). Learned changes in the sensitivity of stimulus representations: Associative and nonassociative mechanisms. Quarterly Journal of Experimental Psychology, 56B, 43-55.

McLaren, I. P. L., Kaye, H., \& Mackintosh, N. J. (1989). An associative theory of the representation of stimuli: Applications to perceptual learning and latent inhibition. In R. G. M. Morris (Ed.), Parallel distributed processing: Implications for psychology and neurobiology (pp. 102-130). Oxford: Oxford University Press, Clarendon Press.

McLaren, I. P. L., \& Mackintosh, N. J. (2000). An elemental model of associative learning: I. Latent inhibition and perceptual learning. Animal Learning \& Behavior, 28, 211-246.

Rescorla, R. A., \& Cunningham, C. L. (1978). Within-compoundflavor associations. Journal of Experimental Psychology: Animal Behavior Processes, 4, 267-275.

WAGNER, A. R. (1981). SOP: A model of automatic memory processing in animal behavior. In N. E. Spear \& R. R. Miller (Eds.), Information processing in animals: Memory mechanisms (pp. 5-47). Hillsdale, NJ: Erlbaum.

(Manuscript received September 20, 2002; revision accepted for publication January 22, 2003.) 